\title{
Effects of Cadmium on the Interactions between Bacterivorous Nematode Species, Acrobeloides nanus and Bursilla monhystera
}

\author{
Clifford P. Bendoy ${ }^{1}$, Vanessa Mae C. Tumang ${ }^{2}$, Queenilyn B. Albutra ${ }^{3}$, \\ Carlo Stephen O. Moneva ${ }^{2}$, Mary Ann M. Ganzon ${ }^{4}$ \\ ${ }^{1}$ Natural Sciences Department, College of Arts and Sciences, \\ Misamis University, Ozamiz City, Philippines \\ ${ }^{2}$ Department of Biological Sciences, College of Science and Mathematics, \\ Mindanao State University - Iligan Institute of Technology, Iligan City, Philippines \\ ${ }^{3}$ Department of Environmental Science and Technology, College of Arts and Sciences, \\ Mindanao University of Science and Technology, Cagayan de Oro City, Philippines \\ ${ }^{4}$ College of Arts and Sciences, St. Michael's College, Iligan City, Philippines \\ Corresponding author: Clifford P. Bendoy, email: cliffordbendoy@yahoo.com
}

\begin{abstract}
Interactions of species have been recognized to play an important role in the structure and functioning of the environment. However, the exact mechanism is not well understood particularly under shifting environmental conditions like pollution. To determine the effects of pollutants/contaminants on the fitness of two soil nematodes (Acrobeloides nanus and Bursilla monhystera) under pristine and polluted condition, we performed experimental set-ups (monoculture and combined cultures) and exposed the organisms to varying sublethal cadmium $(\mathrm{Cd})$ concentrations $(0 \mathrm{mg} / \mathrm{L}, 1.4 \mathrm{mg} / \mathrm{L}$ and $1.9 \mathrm{mg} / \mathrm{L})$. In monoculture, results showed continuous increase in the abundances of $A$. nanus and $B$. monhystera in non-polluted condition. Abundance of $A$. nanus remained increased in polluted condition, however, $B$. monhystera responded negatively to increasing $\mathrm{Cd}$ concentrations. In combination, results in non-polluted condition showed that $B$. monhystera exhibited a negative effect on the abundance of $A$. nanus, suggesting that $B$. monhystera is a stronger competitor than $A$. nanus. However, a shift in abundance pattern was observed when both species were exposed to pollutants particularly on the positive effect by A. nanus on B. monhystera which implies that sublethal $\mathrm{Cd}$ concentrations can potentially alter species interactions. Thorough assessment of nematode interactions is essential in explaining patterns of community structure in disturbed systems and determining proper functioning in the ecosystem.
\end{abstract}

Keywords: abundance, community, competitor, monoculture, pollution 


\section{Introduction}

Nematodes represent a very abundant group of soil organisms, and these non-parasitic species are important for soil quality and in the soil food web (Sochova et al., 2006). They are ubiquitous in aquatic and terrestrial habitats and constitute one of the largest animal phyla. Soil inhabiting nematodes are divided into different feeding groups: plant, bacterial and fungal feeders, predators, and omnivores (Yeates et al., 1993). In recent years, it has been shown that nematodes are appropriate bioindicators of soil condition, and they are also suitable organisms for laboratory toxicity testing (Sochova et al., 2006). Nematodes offer perspectives for ecotoxicological research because of their abundance, species diversity and differences in sensitivity to chemicals (Kammenga et al., 1994) such as cadmium (Alvarez et al., 2006; Kammenga et al., 1994, 1996; Martinez et al., 2012).

Bacterivorous nematodes are said to be the key intermediaries in decomposition processes of organic matter in soil (Freckman, 1988). Studies have shown enhancement of the decomposition process in the presence of nematodes both in terrestrial and aquatic environments (De Mesel et al., 2003; Lillebo et al., 1999).

Like any other organisms, nematodes also interact in several ways. Species interactions are important in shaping the community structure (Ingham et al., 1985; Shannon et al., 1994; van der Heijden et al., 1998; Bongers \& Ferris, 1999; De Mesel et al., 2004; Postma-Blaauw et al., 2005) and in the proper functioning of ecosystems (Shannon et al., 1994). For instance, Postma-Blaauw et al. (2005) found that the contramensal interaction between $B$. monhystera and Plectus parvus affected the bacterial community structure caused by increased biomass and nitrogen mineralization. Gaudes et al. (2013) explained that bacterial-feeding nematodes can affect bacterial communities at different levels, influencing bacterial activity, either positively (Findlay \& Tenore, 1982; Ingham et al., 1985; Alkemade et al., 1992a, b; Traunspurger et al., 1997) or negatively (De Mesel et al., 2003), which may eventually alter the composition and diversity of bacterial communities (De Mesel et al., 2004, 2006).

However, such balance in interaction can be threatened due to increasing heavy metal pollution levels (Fleeger et al., 2003). Heavy metals influence the food availability and competitive interactions among 
species of soil biota in an indirect way (Han et al., 2009). A study of Martinez et al. (2012) demonstrated that sublethal pollution level can change the interaction of two nematode species, $P$. parvus and $A$. nanus owing to their differential tolerance - $P$. parvus being the more sensitive species than $A$. nanus, leading to counterintuitive result such as increase in $A$. nanus fitness during pollution.

In this paper, we would like to determine how do the two bacterivorous nematode species, A. nanus and B. monhystera interact with each other under non-polluted condition, and how do sublethal $\mathrm{Cd}$ levels affect the nature of their interactions. To address these questions, we performed a microcosm experiment using the nematodes A. nanus and $B$. monhystera and exposed them to varying sublethal cadmium concentrations ( $0 \mathrm{mg} / \mathrm{L}, 1.4 \mathrm{mg} / \mathrm{L}$ and $1.9 \mathrm{mg} / \mathrm{L})$ for a period of 40 days.

\section{Materials and Methods}

\section{Preparation of a nematode culture}

Two bacterivorous nematode species belonging to the same trophic group namely Acrobeloides nanus and Bursilla monhystera were used in this experiment. Cultures of these nematodes were obtained from the Department of Biological Sciences Laboratory of Mindanao State University - Iligan Institute of Technology. Nematodes were subcultured in the agar medium and were fed with Escherichia coli, which proved to be a suitable food source of the nematodes ( $\mathrm{Li}$ et al., 2005). The medium was supplied with sterols due to their important role in nematode reproduction (Vanfleteren, 1980).

The experiment was carried out in partitioned and full Petri dishes ( $8 \mathrm{~cm}$ in diameter). These were filled with a $1.5 \%$ bacto-agar medium. Cadmium concentrations were added to the Petri dishes and stirred gently to homogenize with the agar. Sublethal $\mathrm{Cd}$ concentrations used in the study were $1.4 \mathrm{mg} \mathrm{L}^{-1}$ and $1.9 \mathrm{mg} \mathrm{L}^{-1}$. Sublethal concentrations were determined based on the $\mathrm{LC}_{50}$ of $\mathrm{Cd}$ on both $A$. nanus and $P$. parvus (Martinez et al., 2012). Using a fine copper wire, five A. nanus and five $B$. monhystera adults were selected and placed in the partitioned Petri dish (monoculture set-up), and a combination of the nematode species (5 A. nanus : 5 B. monhystera) was placed in full Petri dish (interaction set-up). 
The set-ups were replicated three times, hence the entire experimental set-up included two nematode set-ups (monoculture and combined) and three cadmium concentrations $(0 \mathrm{mg} / \mathrm{L}, 1.4 \mathrm{mg} / \mathrm{L}$ and $1.9 \mathrm{mg} / \mathrm{L}$ ) in four (4) sampling periods, which totalled to 24 plates. All set-ups were sampled destructively after 10, 20, 30 and 40 days. The designed time frame was intended to appropriate at least three generations of each species.

\section{Nematode counts}

Adult nematodes were counted every after 10th, 20th, 30th and 40th day. Nematodes were extracted by dissolving the agar in boiling water while stirring constantly. Samples were sieved out using a $75-\mu \mathrm{m}-\mathrm{mesh}-\mathrm{size}$ sieve and preserved in $2 \%$ formalin solution.

\section{Statistical Analysis}

Statistical analyses were performed using Statistica 7.0 and Paleontological Statistics, PAST software. When all assumptions for ANOVA were met, one-way ANOVA was used to test the equality of the means of the abundances of $A$. nanus and $B$. monhystera. A $p$ value is provided to indicate how close the mean variances are to one another. A $p$ value that is lesser than 0.05 is said to be significant. Exploratory tests via regression line and bar graph with error bars were generated to graphically determine the difference in the abundances of the two nematode species.

\section{Results and Discussion}

\section{Non-polluted condition}

Figure 1 shows the varying abundances of $A$. nanus and $B$. monhystera between monoculture and combined set-ups in non-polluted condition. In monoculture, there was a continuous increase in the abundance of both $A$. nanus and $B$. monhystera from day 1 to 40 . A. nanus has a generation time of 11 days at $20^{\circ} \mathrm{C}$ (Sohlenius, 1973) and can survive for more than 55 days (Kammenga et al., 1994). B. monhystera is characterized by a short generation time and rapid population development at high food availability (Postma-Blaauw et al., 2005). Hence, the increase in the abundances of $A$. nanus and 
B. monhystera was expected because the agar plates provided a suitable place for them to thrive. However, in combination set-up, A. nanus abundance was statistically lower than B. monhystera $(\mathrm{p}<0.05)$. The result suggests that under pristine condition, $B$. monhystera may be the stronger competitor leading to its higher abundances $(p<0.05)$. The general trend in the combination set-up was that the abundance of $A$. nanus was negatively affected by the presence of $B$. monhystera showing asymmetric pattern of intraspecific interaction. This conforms to the asymmetric relationship described by Postma-Blaauw et al. (2005).
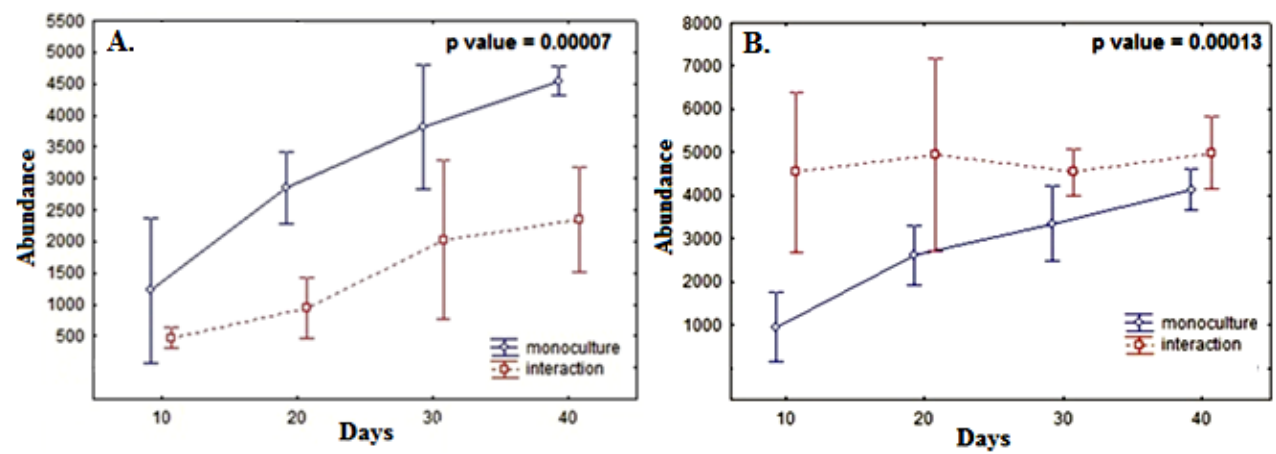

Figure 1. Abundances of adult A. nanus (A) and B. monhystera (B) between monoculture and combination set-ups in non-polluted condition.

Asymmetric competition between species is commonly found in aquatic and aboveground ecosystems, especially with species competing by direct interference (Begon et al., 1996). Different responses among genera in the same trophic group are common (Porazinska et al., 1999), and nematode genera within the same trophic group can exhibit asymmetric competition, negatively influencing the abundance of other genera (Postma-Blaauw et al., 2005). Such interaction outcome may be due to the limited similar food source, which resulted to competition and resource depletion, and in turn increased the competition between species (Martinez et al., 2012). Eventually, uninterrupted competition may lead to inhibition where individuals of one species suffer a reduction in growth, survivorship and fecundity as a consequence of resource exploitation or interference of the other species (Begon et al., 1996; Keddy, 2001). 


\section{Polluted condition}

Figure 2 compares the abundance of $A$. nanus and $B$. monhystera between the monoculture set-up and interaction set-up in different cadmium concentrations. Results showed that the abundance of A. nanus in the monoculture set-up was increasing exponentially across sublethal $\mathrm{Cd}$ concentrations (Figure 2A). The significant increase in abundance of A. nanus monoculture may be attributed to the high tolerance of $A$. nanus to cadmium pollutant $(\mathrm{p}<0.05)$ (Martinez et al., 2012). Increase in $A$. nanus fitness was evident as $\mathrm{Cd}$ concentration increased, but non-existent in the combination cultures. A reduced trend was observed in the combined set-up, however the difference in the abundance of $A$. nanus in all $\mathrm{Cd}$ concentrations was not quite substantial. Statistical value confirms the significant difference $(p=0.00034)$ observed in the abundance of $A$. nanus between two experimental set-ups. The increase in fitness of $A$. nanus even under polluted condition in the monospecific set-up has also been observed in several organisms. According to Calabrese and Baldwin (2001), this is an adaptive response of organisms to low pollutant levels, causing an increase in fitness for a certain period of time. However, such phenomenon was not observed when $A$. nanus was combined with B. monhystera.

On the other hand, $B$. monhystera responded negatively to increasing $\mathrm{Cd}$ concentrations particularly at the highest concentration of $1.9 \mathrm{mg} / \mathrm{L}$ (Figure 2B), which suggests that B. monhystera is more sensitive than $A$. nanus. However, when combined with $A$. nanus, the higher sensitivity of $B$. monystera towards $\mathrm{Cd}$ disappeared. Particularly, at $1.9 \mathrm{mg} / \mathrm{L}$, the abundance in the combination culture exceeded significantly than that of the monoculture experiment $(\mathrm{p}<0.05)$. The rapid increase in the abundance of $B$. monhystera in the combined set-up may be attributed to the high competitory ability of $B$. monhystera where Bursilla populations would show a more rapid response to, and a stronger dependence on nutrient enrichment (Gaudes et al., 2013). 

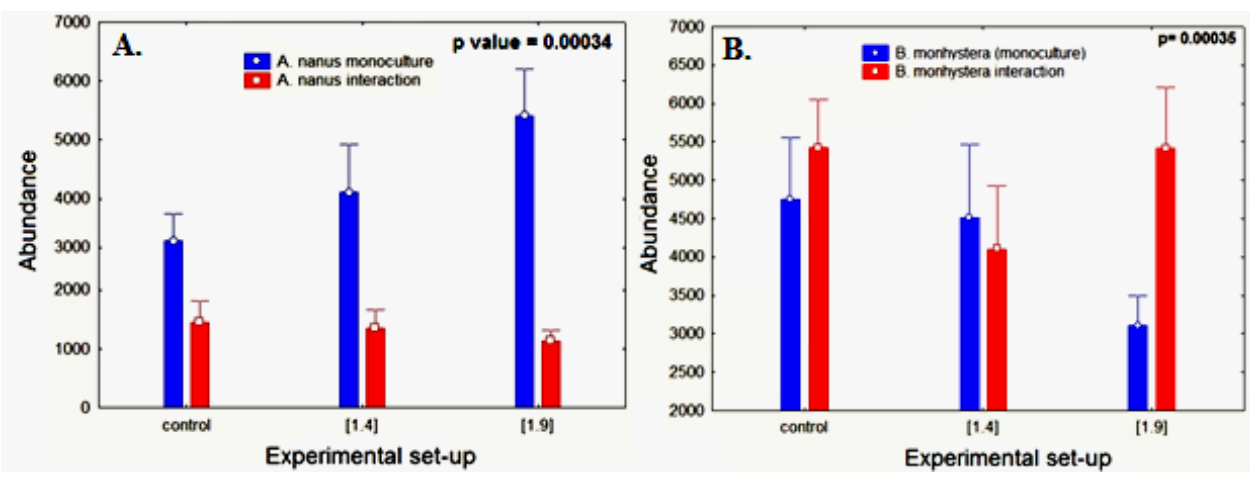

Figure 2. Abundance of $A$. nanus (A) and B. monystera (B) between monoculture and combination cultures treated with varying $\mathrm{Cd}$ concentrations.

It has been demonstrated in several studies that pollutants can alter species interactions (Fleeger et al., 2003; Martinez et al., 2012). Heavy metal pollutants influenced the food availability and competitive interactions among species of soil biota and finally affected the biota communities in an indirect way (Korthals et al., 1996). This was confirmed in our set-up when the presence of varying concentrations of cadmium had significantly altered the interaction of nematodes in the combined set-up. The negative effect on $A$. nanus by $B$. monhystera was evident from non-polluted to polluted condition, indicating that sublethal $\mathrm{Cd}$ level did not alter species interaction. However, there was a shift in the interaction of $B$. monystera as a function of $\mathrm{Cd}$ concentration. The positive effect by $A$. nanus on $B$. monhystera at $0 \mathrm{mg} / \mathrm{L}$ was lost at $1.4 \mathrm{mg} / \mathrm{L}$, but reappeared at the highest $\mathrm{Cd}$ concentration. This may be attributed to the nature of the medium used. Depending on the degree of susceptibility of both species to toxicants, pollutants can dramatically shift the balance of their interaction (Martinez et al., 2012). Possible sublethal effects of metals on population dynamics may include affected generation time, metal accumulation in consecutive generations, and impairment of reproduction (Vranken \& Heip, 1986). The culture medium was relatively poor in nutrient and was composed of a highly purified agar - sterols. The agar might selectively bind metals (Vranken \& Heip, 1986) at higher Cd concentrations and hence reduce their toxicity to $B$. monhystera. 


\section{Conclusions and Recommendations}

Our results confirmed the asymmetric competition between Acrobeloides nanus and Bursilla monhystera. Both in polluted and non-polluted conditions, $B$. monhystera exhibited a negative effect on the abundance of $A$. nanus. When the abundance of the stronger competitor $B$. monhystera increases, the relative abundance of the weaker competitor $A$. nanus inversely decreases. The results obtained also confirm the high sensitivity of $B$. monhystera and high tolerance of $A$. nanus to varying sublethal concentrations of cadmium pollutant. Furthermore, our experiment showed that sublethal concentrations of $\mathrm{Cd}$ can potentially alter species interactions. Future studies aiming to expand such research may consider determining the differential tolerance of the other bacterivorous nematodes to pollutants like zinc, copper and lead. It is also highly recommended to compare different sensitivity among nematode species to assess which species can be used best as bioindicator for toxicity tests.

\section{Acknowledgment}

The authors acknowledge every significant person of the Department of Biological Sciences of MSU-IIT who selflessly extended helpful discussions and tangible concepts, and provided real-time technical assistance. The Nematology Laboratory of the Department of Biological Sciences, MSU-IIT is also acknowledged.

\section{Literature Cited}

Alkemade, R., Wielemaker, A., \& Hemminga, M. A. (1992a). Stimulation of decomposition of Spartina anglica leaves by the bacterivorous marine nematode Diplolaimelloides bruciei (Monhysteridae). Journal of Experimental Marine Biology and Ecology, 159(2), 267-278. doi:10.1016/0022-0981(92)90041-8 
Alkemade, R., Wielemaker, A., de Jong, S. A., \& Sandee, A. J. J. (1992b). Experimental evidence for the role of bioturbation by the marine nematode Diplolaimella dievengatensis in stimulating the mineralization of Spartina anglica detritus. Marine Ecology Progress Series, 90, 149-155.

Álvarez, O. A., Jager, T., Redondo, E. M., \& Kammenga, J. E. (2006). Physiological modes of action of toxic chemicals in the nematode Acrobeloides nanus. Environmental Toxicology and Chemistry, 25(12), 3230-3237. doi: 10.1897/06-097R.1

Begon, M., Harper, J. L., \& Townsend, C. R. (1996). Ecology: Individuals, Populations and Communities (3rd ed.). England, UK: Blackwell Science Oxford.

Bongers, T., \& Ferris, H. (1999). Nematode community structure as a bioindicator in environmental monitoring. Trends in Ecology \& Evolution, 14(6), 224-228. doi:10.1016/ S0169-5347(98)01583-3

Calabrese, E. J., \& Baldwin, L. A. (2001). Hormesis: U-shaped dose responses and their centrality in toxicology. Trends in Pharmacological Sciences, 22(6), 285-291. doi:10.1016/S0165 $-6147(00) 01719-3$

De Mesel, I., Derycke, S., Swings, J., Vincx, M., \& Moens, T. (2003). Influence of bacterivorous nematodes on the decomposition of cordgrass. Journal of Experimental Marine Biology and Ecology, 296(2), 227-242. doi:10.1016/S0022-0981(03)00338-1

De Mesel, I., Derycke, S., Moens, T., Van der Gucht, K., Vincx, M., \& Swings, J. (2004). Top-down impact of bacterivorous nematodes on the bacterial community structure: A microcosm study. Environmental Microbiology, 6(7), 733-744. doi: 10.1111/j. 1462-2920. 2004.00610.x

De Mesel, I., Derycke, S., Swings, J., Vincx, M., \& Moens, T. (2006). Role of nematodes in decomposition processes: Does within-trophic group diversity matter? Marine Ecology Progress Series, 321, 157-166. 
Findlay, S., \& Tenore, K. R. (1982). Effect of a free-living marine nematode (Diplolaimella chitwoodi) on detrital carbon mineralization. Marine Ecology Progress Series, 8(2), 161-166.

Fleeger, J. W., Carman, K. R., \& Nisbet, R. M. (2003). Indirect effects of contaminants in aquatic ecosystems. Science of the Total Environment, 317(1), 207-233. doi:10.1016/ S0048-9697(03) 00141-4

Freckman, D. W. (1988). Bacterivorous nematodes and organic-matter decomposition. Agriculture, Ecosystems \& Environment, 24(1), 195-217. doi:10.1016 / 0167- 8809 (88)90066-7

Gaudes, A., Muñoz, I., \& Moens, T. (2013). Bottom-up effects on freshwater bacterivorous nematode populations: A microcosm approach. Hydrobiologia, 707(1), 159-172. doi: 10.1007/s10750012-1421-5

Han, D., Zhang, X., Tomar, V. V. S., Li, Q., Wen, D., \& Liang, W. (2009). Effects of heavy metal pollution of highway origin on soil nematode guilds in North Shenyang, China. Journal of Environmental Sciences, 21(2), 193-198. doi:10.1016/S10010742(08)62250-0

Ingham, R. E., Trofymow, J. A., Ingham, E. R., \& Coleman, D. C. (1985). Interactions of bacteria, fungi, and their nematode grazers: Effects on nutrient cycling and plant growth. Ecological Monographs, 55(1), 119-140.

Kammenga, J. E., Busschers, M., Van Straalen, N. M., Jepson, P. C., \& Bakker, J. (1996). Stress induced fitness reduction is not determined by the most sensitive life-cycle trait. Functional Ecology, 10(1), 106-111.

Kammenga, J. E., Van Gestel, C. A. M., \& Bakker, J. (1994). Patterns of sensitivity to cadmium and pentachlorophenol among nematode species from different taxonomic and ecological groups. Archives of Environmental Contamination and Toxicology, 27(1), 88-94. 
Keddy, P. A. (2001). Competition (2nd ed.). Dordrecht, The Netherlands: Kluwer Academic Publishers.

Korthals, G. W., de Goede, R. G. M., Kammenga, J. E., \& Bongers, T. (1996). The maturity index as an instrument for risk assessment of soil pollution. In N. M. van Straalen \& D. A. Krivolutsky (Eds.), Bioindicator Systems for Soil Pollutions (pp. 85-93). Netherlands: Kluwer Academic Publishers.

Li, F., Neher, D. A., Darby, B. J., \& Weicht, T. R. (2005). Observed differences in life history characteristics of nematodes Aphelenchus and Acrobeloides upon exposure to copper and benzo (a) pyrene. Ecotoxicology, 14(4), 419-429. doi: 10.1007/s10646$004-1347-4$

Lillebo, A. I., Flindt, M. R., Pardal, M. Â., \& Marques, J. C. (1999). The effect of macrofauna, meiofauna and microfauna on the degradation of Spartina maritima detritus from a salt marsh area. Acta Oecologica, 20(4), 249-258. doi:10.1016/S1146-609X (99)00141-1

Martinez, J. G., dos Santos, G., Derycke, S., \& Moens, T. (2012). Effects of cadmium on the fitness of, and interactions between, two bacterivorous nematode species. Applied Soil Ecology, 56, 10-18. doi:10.1016/j.apsoil.2012.02.001

Porazinska, D. L., Duncan, L. W., McSorley, R., \& Graham, J. H. (1999). Nematode communities as indicators of status and processes of a soil ecosystem influenced by agricultural management practices. Applied Soil Ecology, 13(1), 69-86. doi: 10.1016/S0929-1393(99) 00018-9

Postma-Blaauw, M. B., de Vries, F. T., De Goede, R. G. M., Bloem, J., Faber, J. H., \& Brussaard, L. (2005). Within-trophic group interactions of bacterivorous nematode species and their effects on the bacterial community and nitrogen mineralization. Oecologia, 142(3), 428-439. doi: 10.1007/s00442-004-1741-x 
Shannon, J. P., Blinn, D. W., \& Stevens, L. E. (1994). Trophic interactions and benthic animal community structure in the Colorado River, Arizona, USA. Freshwater Biology, 31(2), 213-220. doi: 10.1111/ j.1365-2427.1994. tb00855.x

Sochova, I., Hofman, J., \& Holoubek, I. (2006). Using nematodes in soil ecotoxicology. Environment International, 32(3), 374-383.

Sohlenius, B. (1973). Growth and reproduction of a nematode Acrobeloides sp. cultivated on agar. Oikos, 24(Fasc. 1), 64-72.

Traunspurger, W., Bergtold, M., \& Goedkoop, W. (1997). The effects of nematodes on bacterial activity and abundance in a freshwater sediment. Oecologia, 112(1), 118-122.

van der Heijden, M. G. A., Boller, T., Wiemken, A., \& Sanders, I. R. (1998). Different arbuscular mycorrhizal fungal species are potential determinants of plant community structure. Ecology, 79(6), 2082-2091.

Vanfleteren, J. R. (1980). Nematodes as nutritional models. In B. M. Zuckerman (Ed.), Nematodes as biological models. Volume 2. aging and other model systems (pp. 47-79). New York, USA \& London: Academic Press, Inc.

Vranken, G., \& Heip, C. (1986). Toxicity of copper, mercury and lead to a marine nematode. Marine Pollution Bulletin, 17(10), 453-457. doi:10.1016/0025-326X(86) 90834-9

Yeates, G. W., Bongers, T., De Goede, R. G. M., Freckman, D. W., \& Georgieva, S. S. (1993). Feeding habits in soil nematode families and genera - An outline for soil ecologists. Journal of Nematology, 25(3), 315-331. 